\title{
Rancang Bangun Alat Monitoring Energi Listrik Pada Kulkas Berbasis Smartphone
}

\author{
Qoriatul Fitriyah $^{*}$, Tri Vira Putri", Aditya Wirangga ${ }^{\#}$, and Muhammad Prihadi Eko Wahyudi* \\ * Batam Polytechnics \\ Electrical Engineering Study Program \\ Jl.Ahmad Yani, Batam Centre, Batam 29461, Indonesia \\ E-mail: fitriyah@polibatam.ac.id.ac.id \\ \#Batam Polytechnics \\ Management Business study Program \\ Jl.Ahmad Yani, Batam Centre, Batam 29461, Indonesia
}

\begin{abstract}
Abstrak
Alat monitoring energi listrik pada kulkas berbasis smartphone ditujukan sebagai bagian dari kampanye penghematan energi. Alat ini bekerja dengan prinsip pengaturan daya pada kulkas berdasarkan parameter temperatur dan waktu penyalaan kulkas. Apabila temperatur kulkas telah stabil, maka kulkas akan otomatis off sehingga konsumsi energi listrik bisa diturunkan. Alat ini juga terhubung dengan aplikasi berbasis Android sehingga kinerja alat juga bisa diatur melalui handphone dengan variabel tertentu.
\end{abstract}

Kata kunci: Efisiensi, Kulkas, Energi Listrik pada Kulkas, Efisiensi Energi Listrik, Aplikasi, Android

\begin{abstract}
Electric energy monitoring device on smartphone-based refrigerators are intended as part of an energy saving campaign. This device works with the principle of regulating the power of the refrigerator based on the parameters of the temperature and starting time of the refrigerator. If the temperature has stabilized, the refrigerator will automatically turned off so that electrical energy consumption can be reduced. This device is also connected to an Android-based application so that the device's performance can also be regulated via mobile phones with certain variables.
\end{abstract}

Keywords: Efficiency, Refrigerator, Electrical Energy of Refrigerator, Electrical Energy Efficiency, App, Android

\section{Pendahuluan}

Pada tahun 2018, total produksi energi primer yang terdiri dari minyak bumi, gas bumi, batubara, dan energi terbarukan mencapai 411,6 MTOE. Sebesar 64\% atau 261,4 MTOE dari total produksi tersebut diekspor terutama batubara dan LNG. Selain itu, Indonesia juga melakukan impor energi terutama minyak mentah dan produk BBM sebesar 43,2 MTOE serta sejumlah kecil batubara kalori tinggi yang diperlukan untuk memenuhi kebutuhan sektor industri [1].

Menurut World Bank, pemakaian listrik per kapita di Indonesia mencapai angka $733,37 \mathrm{kWh}$ pada tahun 2012. Angka ini berada di atas Bangladesh yang setara 283,46 kWh per kapita dan sedikit lebih unggul dari Filipina yang senilai $664,12 \mathrm{kWh}$ per kapita [2]. Adapun total energi listrik yang diproduksi di Indonesia pada tahun yang sama adalah sebesar
204.205,42 GWh yang kemudian naik menjadi 262.661,38 GWh pada tahun 2017 [3]. Dengan kata lain, pertumbuhan produksi energi listrik di Indonesia naik sebesar 28,6\% dalam kurun waktu 5 tahun saja.

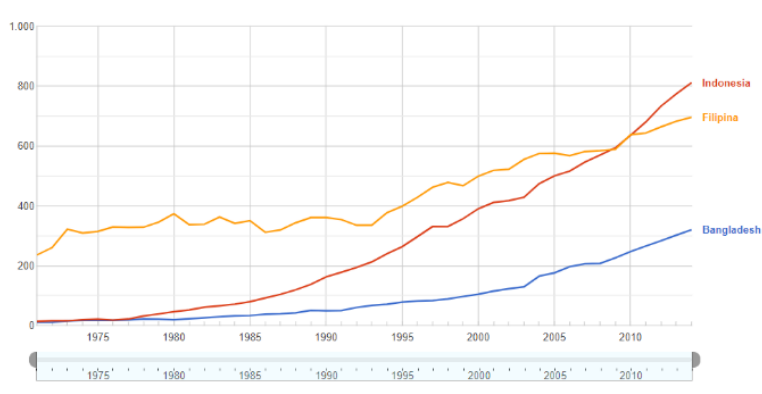

Gambar 1.1 Pemakaian Listrik Per Kapita[2]

Adapun rasio elektrifikasi pada tahun 2017 mencapai angka 94,91\%. Angka ini mengalami kenaikan sebesar 3,75\% dibandingkan tahun 2016 [4]. Rasio 
elektrifikasi adalah perbandingan jumlah rumah tangga yang memiliki pasokan energi listrik dibandingkan dengan jumlah keseluruhan rumah tangga [5].

Menurut ESDM, program pra elektrifikasi, termasuk upaya penggunaan peralatan hemat energi seperti LTSHE, akan menaikkan angka rasio elektrifikasi nasional sebesar $0,02 \%$ [6]. Persentase ini dapat diperbesar dengan upaya pemanfaatan energi terbarukan [6]. Oleh karena itu, penghematan konsumsi listrik diharapkan dapat mendukung program pemerintah untuk mencapai $99 \%$ rasio elektrifikasi pada tahun 2019 [6].

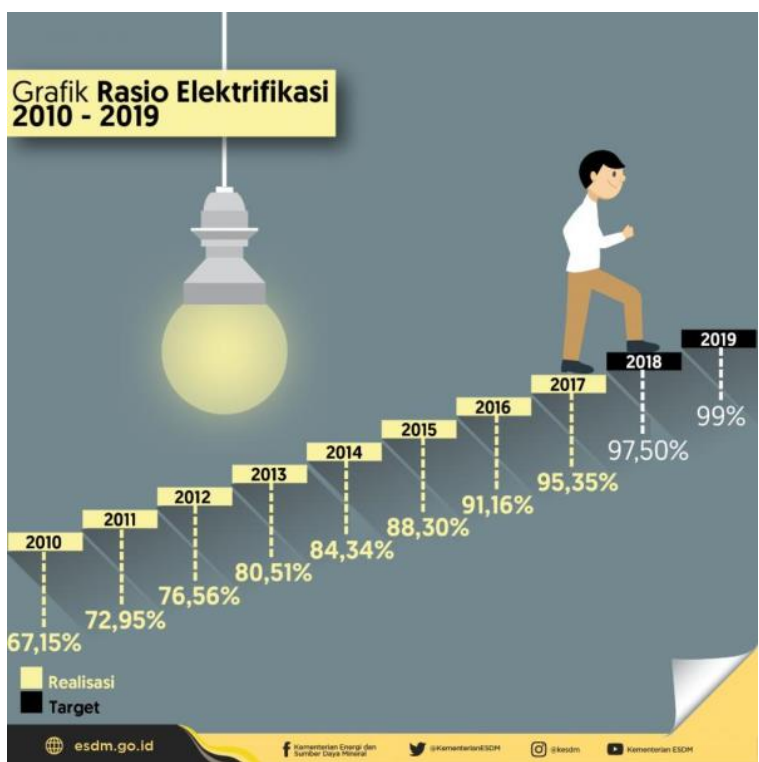

Gambar 1.2 Grafik Rasio Elektrifikasi 2010-2019[6]

Prinsip kerja kulkas bisa dibayangkan sebagaimana konsep pendingin ruangan (air conditioner).

Terdapat empat komponen dasar untuk kulkas yaitu [7]:
1. Evaporator
2. Kompresor
3. Kondenser

4. Alat Ekspansi

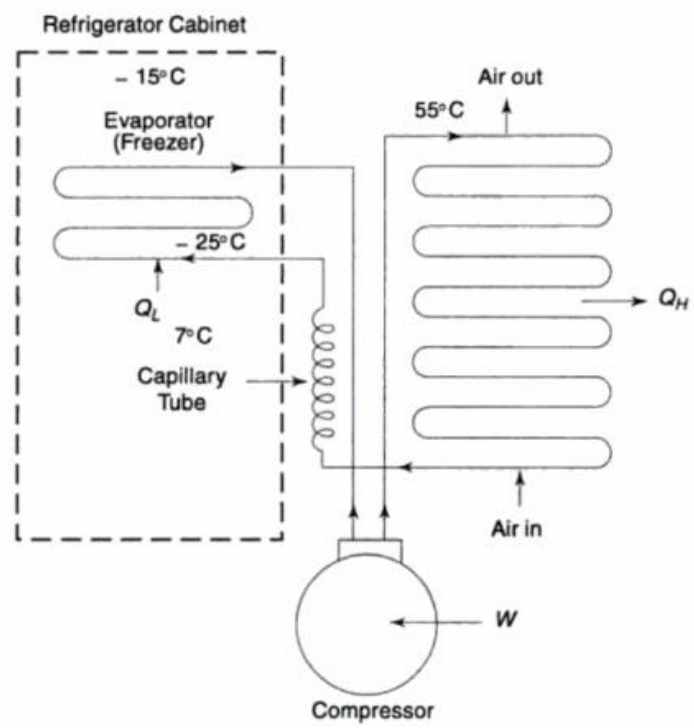

Gambar 1.3 Diagram skematik kulkas rumah tangga[7]

Temperatur merupakan salah satu parameter terukur pada kulkas. Temperatur adalah salah satu indikator dari energi panas yang disimpan pada sebuah benda. Dengan kata lain, kita dapat mengidentifikasi tingkat kepanasan dan kedinginan berdasarkan pada konsep temperatur [8]. Temperatur pada chiller di dalam kulkas sendiri berada pada level $7^{\circ} \mathrm{C}$ [7].

\section{Metode}

\subsection{Perancangan Penelitian}

Tahapan rancangan penelitian yang akan dilakukan dalam perancangan sistem terdiri dari beberapa tahapan penelitian sebagai berikut:

- Perancangan rangkaian elektrik monitoring energi kulkas.

- Pembuatan dan pengujian program pada pembacaan suhu dan daya.

- Pengujian aplikasi ke smartphone dengan module bluetooth.

- $\quad$ Pengambilan data dari kondisi kulkas hidup dan mati.

- Pengujian alat dan analisis data. 


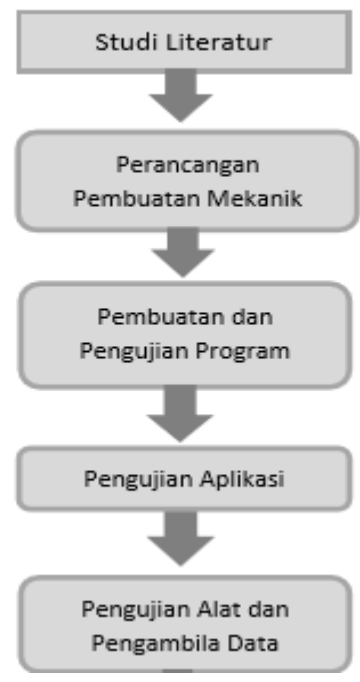

Gambar 2.1 Diagram Blok Rancangan Penelitian

\subsection{Perancangan Alat}

Perancangan alat dipisahkan menjadi tiga yaitu:

\subsubsection{Perancangan Mekanik Alat}

Box Casing merupakan kotak hitam berukuran $18.5 \times 11.5 \times 6.5 \mathrm{~cm}$ yang didesain untuk meletakkan komponen-komponen seperti sensor arus, sensor tegangan, relay, Arduino, dan real time clock. Box Casing diletakkan berdekatan dengan kulkas agar sumber tegangan $\mathrm{AC}$ dapat terhubung dengan adaptor dan sensor temperatur di kulkas.

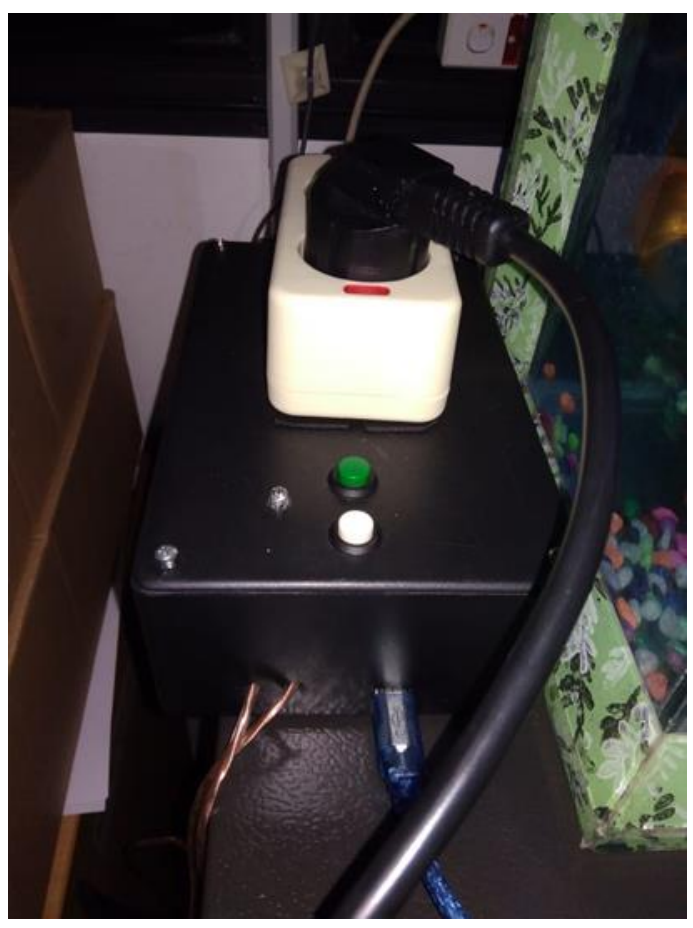

Gambar 2.2.1 Desain Mekanik Alat

\subsubsection{Perancangan Elektrik Alat}

Perancangan elektrikal ini merupakan gabungan wiring antara komponen-komponen yang digunakan seperti sensor arus, sensor tegangan, relay, sensor DHT, RTC, dan modul bluetooth yang kemudian dihubungkan pada Arduino sebagai main processor pada alat ini.

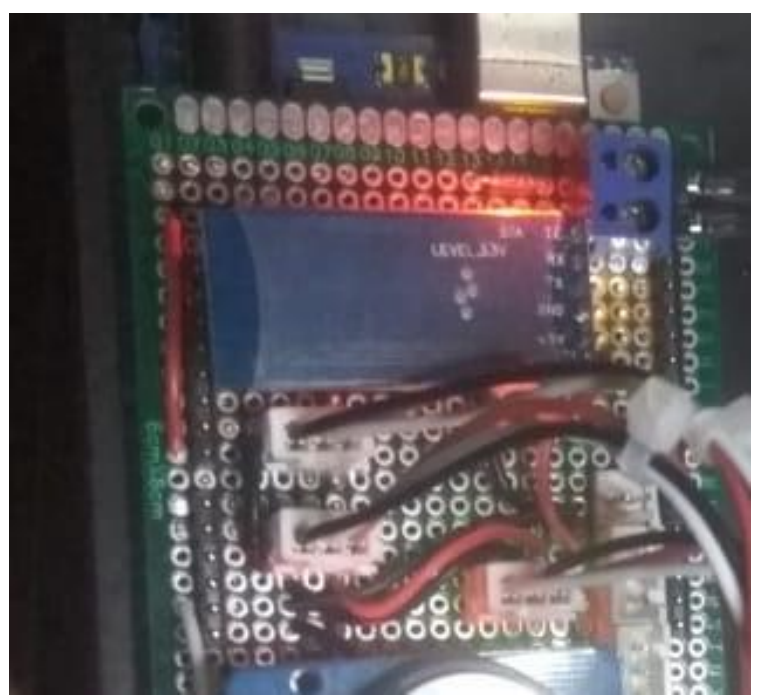

Gambar 2.2.2 Rangkaian Elektrikal Alat

\subsubsection{Perancangan Software (Android App)}

Aplikasi Android berbasis Bluetooth dibangun sebagai perangkat bantu monitoring konsumsi energi listrik pada kulkas. Beberapa parameter yang diamati dan diatur adalah temperatur, waktu, daya realtime dan total konsumsi daya dalam watt hours. Adapun simulasi aplikasi bisa dilihat pada gambar berikut ini:

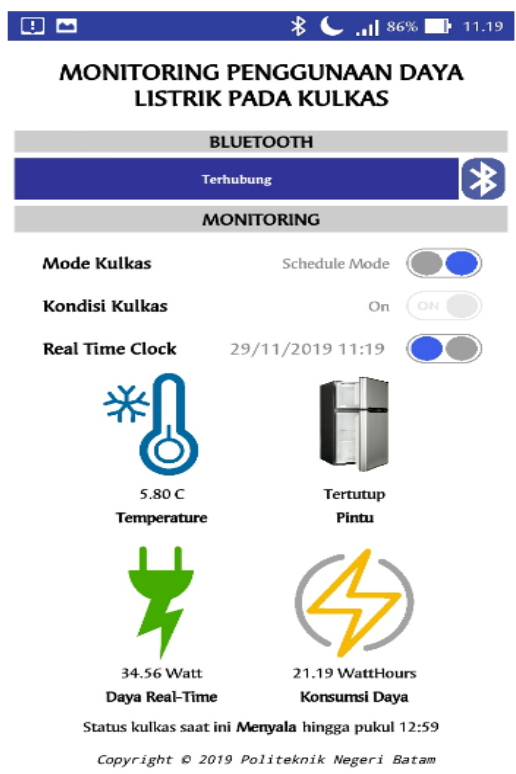

Gambar 2.2.3 Tampilan Aplikasi Monitoring Energi Listrik berbasis Android

\section{Hasil dan Pembahasan}

Berdasarkan hasil uji pengukuran yang dapat dilihat pada Tabel 3.1 menunjukkan bahwa alat telah bekerja dengan baik dan temperatur kulkas mulai stabil setelah 15 menit. 


\begin{tabular}{|c|c|l|c|l|}
\hline Waktu & Suhu Awal & $\begin{array}{l}\text { Keterangan } \\
\text { Suhu Awal }\end{array}$ & Suhu Stabil & $\begin{array}{l}\text { Keterangan } \\
\text { Suhu Stabil }\end{array}$ \\
\hline 14:30 WIB & $\begin{array}{c}\text { 21-24 derajat } \\
\text { celcius }\end{array}$ & $\begin{array}{l}\text { Diawal } \\
\text { percobaan } \\
\text { kulkas baru } \\
\text { dihidupkan } \\
\text { suhu kulkas } \\
\text { sama dengan } \\
\text { suhu ruangan }\end{array}$ & $6-7$ derajat celcius & $\begin{array}{l}\text { Suhu mulai } \\
\text { stabil dalam } \\
\text { waktu 15 menit }\end{array}$ \\
\hline $15: 20$ WIB & $\begin{array}{c}20-21 \text { derajat } \\
\text { celcius }\end{array}$ & & $\begin{array}{l}5.1-6.6 \text { derajat } \\
\text { celcius }\end{array}$ & $\begin{array}{l}\text { Suhu mulai } \\
\text { stabil dalam } \\
\text { waktu 15 menit }\end{array}$ \\
\hline $15: 30 \mathrm{WIB}$ & $\begin{array}{c}17-18 \text { derajat } \\
\text { celcius }\end{array}$ & & $\begin{array}{c}5.4-6.1 \text { derajat } \\
\text { celcius }\end{array}$ & $\begin{array}{l}\text { Suhu mulai } \\
\text { stabil dalam } \\
\text { waktu 17 menit }\end{array}$ \\
\hline
\end{tabular}

Tabel 3.1 Hasil Uji Coba Penelitian

Adapun spesifikasi pengujian kulkas adalah sebagai berikut:

- $\quad$ Sistem Pendingin : Pendinginan Langsung

- Tegangan : 220 Volt

- $\quad$ Frekuensi : $50 \mathrm{~Hz}$

- Daya : 74 Watt

- Arus : 0,6 Ampere

- $\quad$ Dimensi luar (mm) : 570 x 1261 x 585

Aplikasi Android berbasis Bluetooth juga bisa bekerja dengan baik dan segera merespon kondisi real-time pada kulkas, termasuk indikator pintu kulkas yaitu waktu buka dan tutupnya kulkas.

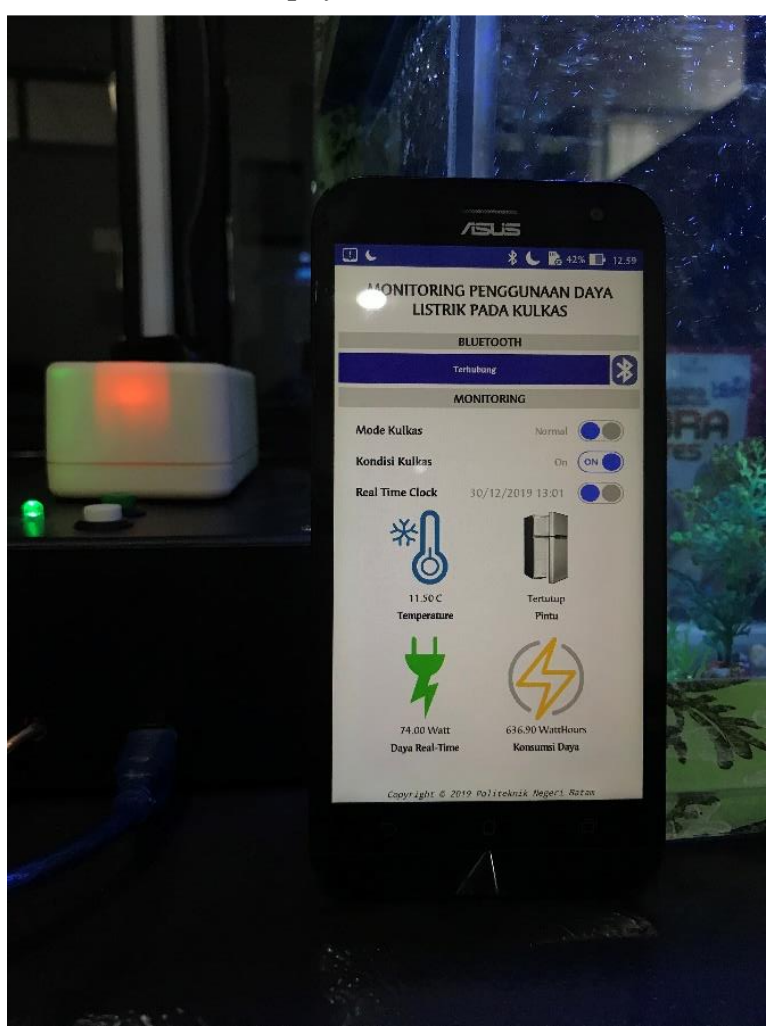

Gambar 3.1 Tampilan Aplikasi ketika Perangkat Elektrik Menyala

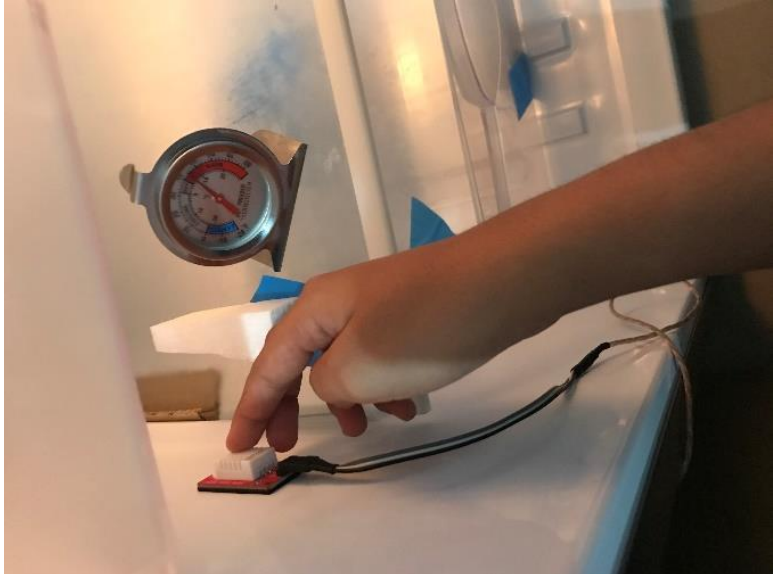

Gambar 3.2 Peletakan Sensor di Dalam Chiller

\section{Kesimpulan}

Dari hasil pegujian yang dilakukan, kesimpulan yang dapat diambil adalah:

1. Pemakaian energi listrik pada kulkas dapat dimonitor dengan menggunakan aplikasi pada smartphone.

2. Monitoring yang dilakukan maksimum sepanjang 100 meter terkait dengan kapasitas bluetooth.

\section{Ucapan Terima Kasih}

Terima kasih kepada P2M Politeknik Negeri Batam selaku sponsor utama penelitian ini.

\section{Referensi}

[1] NASIONAL, S.J.D.E., ENERGI INDONESIA OUTLOOK. 2019: Jakarta.

[2] Bank, W. Pemakaian Listrik Per Kapita. 2012; Available from: https://data.worldbank.org/indonesian?cid= GPDid 28.

[3] Samudin Harsanto, S.S., Statistik Energi Indonesia BPS 2012-2017. 2017, BPS Indonesia: Jakarta.

[4] Mineral, K.E.d.S.D. Rasio Elektrifikasi 2017 Melebihi Target. 2017; Available from: https://www.esdm.go.id/id/beritaunit/direktorat-jenderalketenagalistrikan/rasio-elektrifikasi-2017melebihitarget\#: : :text=Tahun $\% 202017 \% 201$ lalu $\% 2 C$ $\% 20$ prognosa $\% 20$ rasio,mencapai\%20angka $\% 2094 \% 2 \mathrm{C} 91 \% 25$.

[5] Arindya, R., Efektivitas Organisasi Tata 
Kelola Minyak dan Gas Bumi. 2019, Surabaya: Penerbit Media Sahabat Cendekia.

[6] Energi, D.J.E.B.T.d.K. Menuju Rasio Elektrifikasi 99 Persen pada 2019. 2019; Available from: http://ebtke.esdm.go.id/post/2018/04/27/194 5/menuju.rasio.elektrifikasi.99.persen.pada. 2019?lang=en.

[7] Arora, C.P., Refrigeration and Air Conditioning. 2006, New Delhi: Tata McGraw-Hill Publishing Company Limited.

[8] Dincer, I., Refrigeration Systems and Application. 2017, Sussex: Wiley. 